\title{
CTLA4-CD28 chimera gene modification of T cells enhances the therapeutic efficacy of donor lymphocyte infusion for hematological malignancy
}

\author{
Hyung Bae Park ${ }^{1,2,3}$, Ji Eun Lee ${ }^{1,3,4}$, Yu Mi Oh ${ }^{1,3}$, Sang Jin Lee ${ }^{5}$, Hyeon-Seok Eom ${ }^{3,6}$ and Kyungho Choi ${ }^{1,2,4}$
}

Donor lymphocyte infusion (DLI) followed by hematopoietic stem cell transplantation has served as an effective prevention/ treatment modality against the relapse of some hematologic tumors, such as chronic myeloid leukemia (CML). However, the therapeutic efficacies of DLI for other types of leukemia, including acute lymphocytic leukemia (ALL), have been limited thus far. Therefore, we examined whether increasing the reactivity of donor T cells by gene modification could enhance the therapeutic efficacy of DLI in a murine model of ALL. When a CTLA4-CD28 chimera gene (CTC28) in which the intracellular signaling domain of CTLA4 was replaced with the CD28 signaling domain was introduced into CD4 and CD8 T cells in DLI, the graft-versus-tumor (GVT) effect was significantly increased. This effect was correlated with an increased expansion of donor CD8 T cells in vivo, and the depletion of CD8 T cells abolished this effect. The CD8 T cell expansion and the enhanced GVT effect were dependent on the transduction of both CD4 and CD8 T cells with CTC28, which emphasizes the role of dual modification in this therapeutic effect. The CTC28-transduced T cells that expanded in vivo also exhibited enhanced functionality. Although the potentiation of the GVT effect mediated by the CTC28 gene modification of T cells was accompanied by an increase of graft-versus-host disease (GVHD), the GVHD was not lethal and was mitigated by treatment with IL-10 gene-modified third-party mesenchymal stem cells. Thus, the combined genetic modification of CD4 and CD8 donor T cells with CTC28 could be a promising strategy for enhancing the therapeutic efficacy of DLI.

Experimental \& Molecular Medicine (2017) 49, e360; doi:10.1038/emm.2017.104; published online 28 July 2017

\section{INTRODUCTION}

Systemic chemotherapy and radiotherapy are the main treatments for hematologic malignancies because hematologic tumor cells are susceptible to these modalities. However, these treatments can also lead to bone marrow suppression, which necessitates allogeneic hematopoietic stem cell transplantation (HSCT) to reconstitute the hematopoietic and immune systems. ${ }^{1,2}$ Although high-dose chemo/radiotherapy prior to HSCT (that is, myeloablative conditioning) maximizes tumor cell killing and thus exhibits an excellent response rate, it is too toxic for older patients and patients with poor general conditions and is often accompanied with unwanted side effects, such as increased probabilities of infection and severe inflammation., ${ }^{2,3}$ Therefore, reduced intensity chemo/radiotherapy prior to HSCT (that is, non-myeloablative conditioning) is widely performed. ${ }^{4-6}$ In this situation, mixed bone marrow chimerism is established by the remaining recipient and incoming donor hematopoietic cells, and the recipient hematopoietic cells are then gradually eliminated by a small population of mature donor $\mathrm{T}$ cells that is included in the donor bone marrow graft, which leads to full donor chimerism. During this process, residual hematologic malignant cells are also killed primarily by the allogeneic donor $\mathrm{T}$ cell responses against the mismatched major or minor histocompatibility antigens of the recipient tumors; this process is referred to as the graft-versus-tumor (GVT) effect. ${ }^{7}$ However,

\footnotetext{
${ }^{1}$ Department of Biochemistry and Molecular Biology, Seoul National University College of Medicine, Seoul, Republic of Korea; ${ }^{2}$ Department of Biomedical Sciences, Seoul National University College of Medicine, Seoul, Republic of Korea; ${ }^{3}$ Hematologic Malignancy Branch, Research Institute National Cancer Center, Gyeonggi-do, Republic of Korea; ${ }^{4}$ Cancer Research Institute, Seoul National University College of Medicine, Seoul, Republic of Korea; ${ }^{5}$ Genitourinary Cancer Branch, Research Institute National Cancer Center, Gyeonggi-do, Republic of Korea and ${ }^{6}$ Department of Hematology-Oncology, Center for Hematologic Malignancy, National Cancer Center, Gyeonggi-do, Republic of Korea

Correspondence: H-S Eom, Department of Hematology-Oncology, Center for Hematologic Malignancy, National Cancer Center, 323 Ilsan-ro, Ilsandong-gu, Goyang-si, Gyeonggi-do 10408, Republic of Korea.

E-mail: hseom@ncc.re.kr

or Professor K Choi, Department of Biochemistry and Molecular Biology, Seoul National University College of Medicine, 103 Daehak-ro, Jongno-gu, Seoul 03080, Republic of Korea.

E-mail: khchoi@snu.ac.kr

Received 23 January 2017; revised 26 January 2017; accepted 31 January 2017
} 
non-myeloablative conditioning is relatively insufficient for eradicating malignant cells compared with myeloablative conditioning, and full donor chimerism is not established in some patients, which results in a higher relapse rate. ${ }^{8,9}$

Based on the notion that mature donor $\mathrm{T}$ cells can induce the GVT effect, the additional infusion of mature donor lymphocytes (that is, donor lymphocyte infusion, DLI) was introduced to prevent or treat tumor relapse after HSCT. ${ }^{10,11}$ The infused donor lymphocytes are not rejected by the recipient $\mathrm{T}$ cells due to donor-specific tolerance established by the allogeneic HSCT, while they can eliminate recurring malignant cells via the GVT effect. Thus, DLI can be regarded as an early form of adoptive $\mathrm{T}$ cell therapy and is currently widely used in clinical practice in the treatment of many hematologic malignancies. ${ }^{12}$ Although DLI is an effective treatment for certain leukemias (for example, chronic myeloid leukemia (CML) which exhibits a $70-80 \%$ response rate), its efficacy in the treatment of other leukemias remains low (for example, acute myeloid leukemia (AML) and acute lymphocytic leukemia (ALL) for which the response rates are 10-35\%). ${ }^{13-15}$ Therefore, it is necessary to develop new strategies to enhance therapeutic efficacy of DLI for relapsed hematologic tumors. ${ }^{16}$

Another problem related to DLI is the detrimental and often life-threatening side effect called graft-versus-host disease (GVHD). In GVHD, the mature donor T cells attack alloantigens in the normal recipient tissues in addition to those in the tumors. ${ }^{17}$ Conceptually, the GVT effect and GVHD are mediated by the same anti-alloantigen T-cell responses. Hence, it is difficult to separate the two phenomena. ${ }^{18,19}$ Nonetheless, GVHD is preferentially induced in solid organs, such as the intestines, liver, and skin, when those tissues are highly inflamed, whereas the GVT effect typically occurs in lymphoid organs. Highly inflammatory environments in target tissues facilitate the extravasation of activated $\mathrm{T}$ cells and the development of GVHD. ${ }^{20,21}$ Thus, reducing inflammation in GVHD-target organs could represent a method for avoiding GVHD while preserving the beneficial GVT effect of DLI. Accordingly, when DLI was performed in an established mixed bone marrow chimera at approximately two months after HSCT in a mouse model, at which point the inflammation induced by the conditioning process had sufficiently subsided (that is, delayed DLI), the GVT effect was achieved without GVHD. ${ }^{22}$

In clinical settings, prophylactic DLI is usually performed in patients without GVHD after 2 months off immunosuppression if the chimerism is not fully converted to the donor type or is being lost. In a study of DLI following $\mathrm{T}$ cell-depleted allogeneic HSCT for AML and myelodysplastic syndrome, prophylactic DLI elicited a 5-year overall survival of $80 \%$ with a low incidence of GVHD. ${ }^{23}$ Therefore, delayed DLI might be a good starting point for the further development of enhanced allogeneic T-cell therapy with reduced side effects. Other methods of controlling GVHD have also been actively studied, including $\mathrm{T}$ cell trafficking blockade, ${ }^{24,25}$ suicidal gene-transduced DLI, ${ }^{26-29}$ immunosuppressive cell therapies using regulatory $\mathrm{T}$ cells $\mathrm{s}^{30,31}$ and mesenchymal stem cells, ${ }^{32,33}$ etc.

A recent approach in anti-tumor T-cell therapy is the genetic modification of $\mathrm{T}$ cells prior to infusion with the aim of increasing tumor-specificity or enhancing T-cell functionality. ${ }^{34,35}$ We previously reported one such approach using a novel dominant negative CTLA4 mutant, that is, the CTLA4-CD28 chimera (CTC28). ${ }^{36}$ CTLA4 is known as an inhibitory receptor that is present on activated T-cell surfaces, and the neutralization of this receptor with antibodies, such as ipilimumab, increases the overall $\mathrm{T}$ cell reactivity, which contributes to tumor regression. ${ }^{37-39}$ CTC28 is composed of the extracellular and transmembrane domains of CTLA4 and the intracellular domain of CD28. CTC28 gene-modified $\mathrm{T}$ cells can negate negative CTLA4 signaling via the dominant negative effect of CTC28 and can additionally be stimulated via the stimulatory CD28 signaling of CTC28. When CTC28 geneintroduced tumor antigen-specific $\mathrm{T}$ cells are infused into tumor-bearing mice, these $\mathrm{T}$ cells can lead to significant tumor regression. Thus, CTC28 gene-modified T-cell therapy has been proven effective in autologous T-cell therapy models. However, the effect of CTC28 gene-modified T cell therapy in allogenic T-cell therapy models, such as DLI, has not yet been tested.

In this study, we investigated whether the CTC28 gene modification of donor $\mathrm{T}$ cells could enhance the therapeutic efficacy of DLI in a delayed DLI model involving a murine hematologic malignancy. CTC28-transduced DLI cells exhibited robust expansion in the tumor-bearing recipients and elicited an enhanced GVT effect. This gene modification was accompanied by newly developed GVHD, but the GVHD was not lethal and could be alleviated by the co-administration of an immune suppressive cell population of IL-10-secreting mesenchymal stem cells. Thus, CTC28 gene modification of allogeneic donor T cells could be a novel strategy for improving DLI following allogeneic HSCT for hematologic malignancies.

\section{MATERIALS AND METHODS}

\section{Mice}

C57BL/6 (B6, H-2 $\left.{ }^{\mathrm{b}}\right)$ mice were purchased from Orient Bio, Inc. (Seongnam-si, Korea). B10.A (H-2 $\left.{ }^{\mathrm{a}}: \mathrm{K}^{\mathrm{k}}, \mathrm{A}^{\mathrm{k}}, \mathrm{E}^{\mathrm{k}}, \mathrm{D}^{\mathrm{d}}, \mathrm{L}^{\mathrm{d}}\right)$ mice were acquired from SLC, Inc. (Hamamatsu-shi, Shizuoca, Japan). The mice were housed in a specific pathogen-free (SPF) animal facility at the Research Institute National Cancer Center (Korea) and maintained in accordance with the guidelines of the Institutional Animal Care and Use Committee (IACUC). The experimental use of animals was approved by the IACUC (NCC-15-255).

\section{Cells and plasmids}

EL4 cells (a T-cell lymphoma cell line derived from B6) and 2.43 hybridomas (used to produce anti-mouse CD8 antibodies (Ab)) were purchased from the American Type Culture Collection (ATCC, Manassas, VA, USA). Phoenix GP and Phoenix Eco cell lines were provided by Garry Nolan (Stanford University, USA). D3116, a mouse mesenchymal stem cell (MSC) clone, was kindly provided by Sun U. Song (Inha University, Incheon, Korea). ${ }^{40}$ The MSCV retroviral plasmids with IRES-GFP (pMIG) and pMIG containing 
murine IL-10 cDNA (pMIG-IL-10) were kind gifts from Il-Hoan Oh (The Catholic University, Korea). ${ }^{41}$ IL-10 retrovirus-producing and the empty vector (EV) retrovirus-producing Phoenix Eco packaging cell lines were generated using pMIG-IL-10 and pMIG according to a previously described method. ${ }^{36}$ IL-10-transduced and EV-transduced D3116 cells were generated by spin infection with the retroviral supernatants and cell sorting of the GFP-positive population with a FACSAria cell sorter (Becton Dickinson, Franklin Lakes, NJ, USA). IL-10 production from MSCs was quantified by measuring the amount of IL-10 accumulated in the culture supernatant over a $48 \mathrm{~h}$-culture period by ELISA (BD OptEIA mouse IL-10 ELISA Set, BD Biosciences, San Jose, CA, USA).

\section{Transduction of $\mathrm{T}$ cells with the retrovirus}

The retroviral supernatants containing the CTLA4-CD28 chimera retrovirus and the empty-vector retrovirus were generated as previously described. ${ }^{36}$ The retroviruses also encoded the IRES-GFP module to enable the tracing of the transduced cells (pMIG-w). For the retroviral transduction of T cells, spleen and lymph node cells were isolated from B10.A mice and stimulated with plate-bound anti-CD3 $\left(10 \mu \mathrm{g} \mathrm{ml}^{-1}, 145-2 \mathrm{C} 11\right)$ and anti-CD28 $\left(2 \mu \mathrm{g} \mathrm{ml}^{-1}, 37.51\right)$ antibodies (BD Biosciences). After $24 \mathrm{~h}$, the $\mathrm{T}$ cells were transduced with the concentrated retroviruses by centrifugation of the cells at 2500 r.p.m. for $90 \mathrm{~min}$ (spin infection). This procedure was repeated once on the same day. During the spin infection, $6 \mu \mathrm{g} \mathrm{ml}{ }^{-1}$ Polybrene (Sigma-Aldrich, St Louis, MO, USA) was added to the culture supernatant to enhance the transduction efficiency. After $48 \mathrm{~h}$, the transduced $\mathrm{T}$ cells were transferred into fresh medium containing $20 \mathrm{U} \mathrm{ml}^{-1}$ recombinant mouse IL-2 (Invitrogen, Waltham, MA, USA) and allowed to rest for $72 \mathrm{~h}$ without stimulation. After resting, more than $95 \%$ of the live cells were CD4 or CD8 T cells. The cells were stained with phycoerythrin (PE)-conjugated anti-CTLA4 antibody (UC10-4F10-11, BD Biosciences) and analyzed by flow cytometry to measure the expression of GFP and cell surface CTC28.

\section{Bone marrow transplantation}

Recipient B6 mice were lethally irradiated (9 Gy in two split doses separated by $4 \mathrm{~h}$ ). The next day, the mice were intravenously injected with a mixture of $\mathrm{T}$ cell-depleted donor (B10.A, $1.5 \times 10^{7}$ cells) and recipient $\left(\mathrm{B} 6,0.5 \times 10^{7}\right.$ cells) bone marrow $(\mathrm{BM})$ cells. The $\mathrm{BM}$ cells were isolated from the tibias and femurs of the mice, and the T cells were depleted using a cocktail of anti-Thy1.2 (30-H12), anti-CD4 (GK1.5), and anti-CD8 (53-6.7) antibodies (BD Biosciences), and guinea pig complement (Cedarlane, Burlington, ON, Canada) as previously described. ${ }^{42}$ Mixed chimerism in peripheral blood was assessed 5-7 weeks after BMT by flow cytometry (FACSCalibur, Becton Dickinson) and analyzed with FlowJo software (TreeStar, Inc., Ashland, OR, USA). Fluorescein isothiocyanate (FITC)-conjugated anti-H-2D ${ }^{\mathrm{d}}$ (34-2-12, BD Biosciences) or PE-conjugated anti-H-2K $\mathrm{K}^{\mathrm{b}}$ antibody (AF6-88.5.5.3, eBioscience, San Diego, CA, USA) was used to distinguish between the donor $\left(\mathrm{H}-2 \mathrm{D}^{\mathrm{d}}\right)$ and recipient $\left(\mathrm{H}-2 \mathrm{~K}^{\mathrm{b}}\right)$ hematopoietic cells. The donor B10.A mice were aged 5-6 weeks, and the recipient B6 mice were aged 9-12 weeks at the time of BMT. The recipients were provided with antibiotics in their drinking water for 5 weeks beginning at 1 week before bone marrow transplantation (BMT).

\section{Donor lymphocyte infusion}

At least 8 weeks after BMT, the mixed chimera recipient mice were intravenously injected with EL4 $\left(1 \times 10^{4}\right)$ cells. In the preventive model, naive DLI was performed 7 days before EL4 injection. In the therapeutic models, donor lymphocyte infusion (DLI) was performed 4-6 h after EL4 injection. For the naive DLI, splenocytes were isolated from B10.A mice, and the red blood cells (RBC) were removed with ACK-lysis buffer. Single-cell suspensions $\left(2 \times 10^{7}\right.$ cells $)$ were intravenously administered to the recipient mice. For the activated DLI, B10. A splenocytes were stimulated with anti-CD3 and anti-CD28 antibodies. After $72 \mathrm{~h}$, the $\mathrm{T}$ cells were transferred into fresh medium containing $20 \mathrm{U} \mathrm{ml}^{-1}$ mouse IL-2 and rested for $72 \mathrm{~h}$ without stimulation. The $\mathrm{T}$ cells were collected and administered $\left(5 \times 10^{6}\right.$ cells $)$ to the recipient mice by intravenous injection. For the unfractionated CTC28-transduced DLI, T-cell transduction was performed as described above, and the cells $\left(5 \times 10^{6}\right)$ were intravenously injected into the mice. For the fractionated CTC28transduced DLI, CD4 and CD8 T cells were purified from B10.A mice by positive selection using CD4 and CD8 microbeads (Miltenyi Biotec, Bergisch Gladbach, Germany), and $\mathrm{T}$ cell transduction was performed as described above. The transduced CD4 and CD8 T cells were mixed in a 1:1 ratio and administered $\left(3-5 \times 10^{6}\right.$ cells each) by intravenous injection. The survival of the mice was monitored until 70-80 days after tumor injection.

For the in vivo CD8 $\mathrm{T}$ cell depletion study, anti-CD8 antibody $\left(100 \mu \mathrm{l}\right.$ of ascitic fluid from hybridoma $\left.2.43, \sim 10 \mathrm{mg} \mathrm{ml}^{-1}\right)$ was injected every other day for the first week after DLI and subsequently injected once per week for the following 4 weeks. CD8 T cell depletion of more than $98 \%$ in the peripheral blood was confirmed via flow cytometry. Normal rat IgG (1 mg, Sigma-Aldrich) was injected according to the same schedule into the control group of recipient mice.

In some experiments, D3116 MSCs or IL-10-transduced D3116 MSCs $\left(1.5 \times 10^{6}\right.$ cells per an injection per mouse) were intraperitoneally injected into the recipients three times at 7-day intervals beginning on the day of DLI.

\section{Peripheral blood analysis following DLI}

After DLI in the tumor-bearing mixed chimera mice, the presence of DLI cells and the mixed chimerism shift were evaluated at various times. Peripheral blood samples were collected, and the RBCs were then lysed with ACK-lysis buffer. The modified donor T cells were traced as GFP-positive cells via flow cytometry. The shift in the ratio of the mixed chimerism in the blood was periodically analyzed by staining the blood cells with allophycocyanin (APC)-conjugated anti-CD4 (RM4-5, BD Biosciences), PE-Cy5-conjugated anti-CD8 (53-6.7, BD Biosciences), and PE-conjugated $\mathrm{H}-2 \mathrm{~K}^{\mathrm{b}}$ (AF6-88.5.5.3, eBioscience) antibodies.

\section{Intracellular cytokine staining}

Splenocytes were isolated from the recipient mice 10-11 days after tumor injection and DLI. The cells were stimulated with $50 \mathrm{ng} \mathrm{ml}^{-1}$ phorbol 12-myristate 13-acetate (PMA, Sigma-Aldrich) plus $500 \mathrm{ng} \mathrm{ml}^{-1}$ ionomycin (Sigma-Aldrich) for $4 \mathrm{~h}$ in the presence of Golgi-plug (BD Biosciences). After fixation in $4 \%$ paraformaldehyde in PBS for $10 \mathrm{~min}$, the cells were permeabilized with $0.5 \%$ Triton $\mathrm{X}-100$ buffer and then intracellularly stained with APC-conjugated anti-mouse IFN- $\gamma$ antibody (XMG1.2, BD Biosciences). GFP-positive CD4 or CD8 cells were gated and analyzed for IFN- $\gamma$ fluorescent intensity via flow cytometry. 

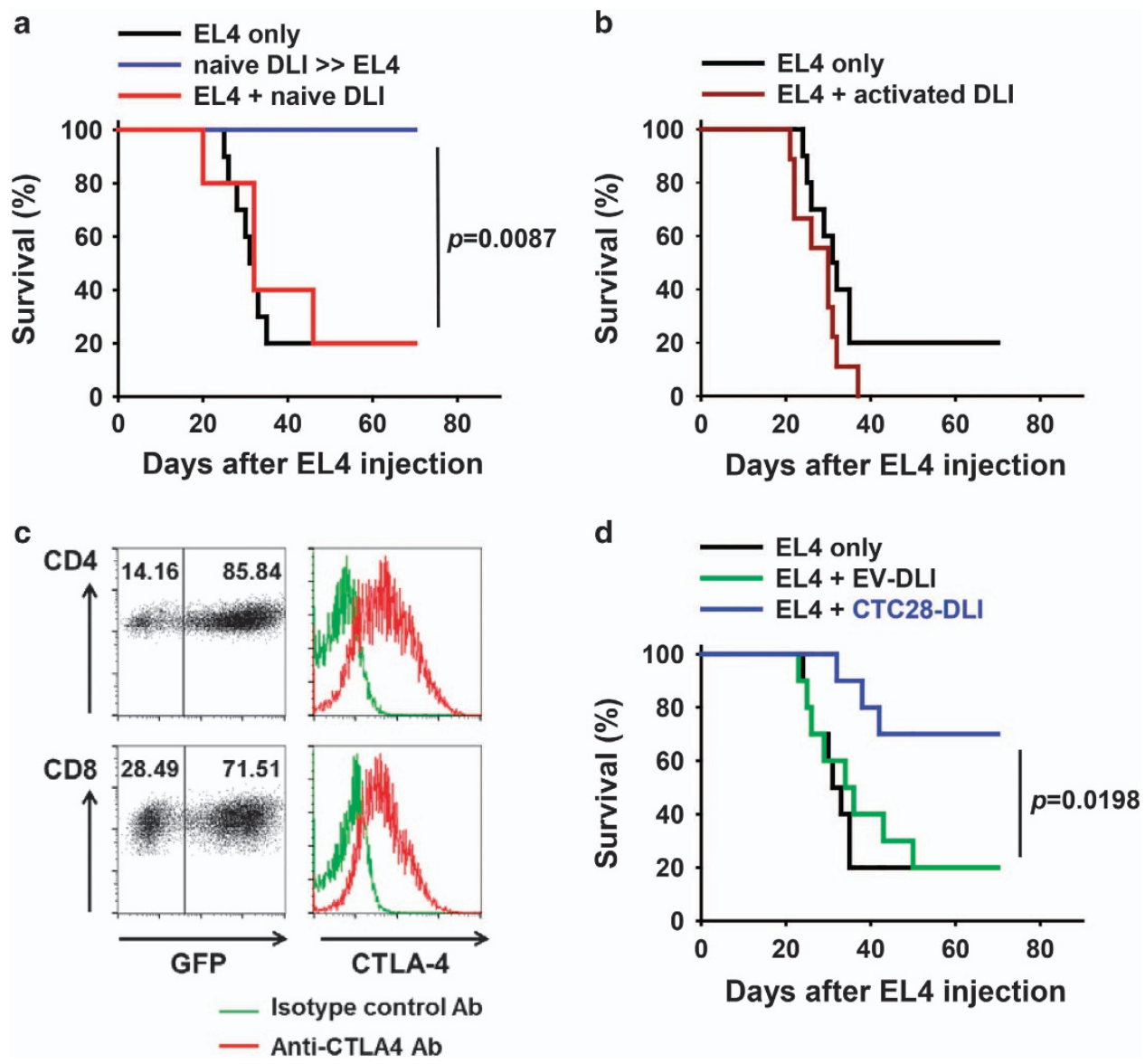

Figure 1 CTC28 gene modification of T cells increases the GVT effect in a therapeutic model of delayed DLI. Lethally irradiated B6 mice were reconstituted with a mixture of T cell-depleted BM cells from B10.A and B6 mice and left unmanipulated for at least 8 weeks (mixed chimera mice) before i.v. EL4 injection. (a) B10.A splenocytes were i.v. administered to the mice 7 days before EL4 injection (naive DLI » EL4) or 4-6 h after EL4 injection (EL4+ naive DLI). A group of the mice was injected with EL4 cells without DLI (EL4 only). The survival of the mice was monitored ( $P$-value: naive DLI $\gg$ EL4 vs EL4 only). (b) B10.A splenocytes that were activated as described in the Materials and Methods section were i.v. administered to the mice 4-6 h after EL4 injection (EL4+activated DLI). (c and d) CD4 and CD8 T cells purified from B10.A mice were activated with anti-CD3 and anti-CD28 and subsequently transduced with CTC28 retrovirus respectively. After resting, both cells types were analyzed for transduction efficiency (GFP-positivity) and cell surface expression of CTC28 via flow cytometry (c) or i.v. administered to the mice as a mixed population at a 1:1 ratio 4-6 h after EL4 injection (EL4+CTC28-DLI) (d). The mixed CD4 and CD8 cells that were transduced with the empty vector (EV) retrovirus were used as a negative control (EL4+EV-DLI) ( $P$-value: EL4+CTC28-DLI vs EL4+EV-DLI). The data were pooled from two independent experiments using five mice per group (a, $\mathbf{b}$ and d). $P$-values from log-rank (Mantel-Cox) tests.

\section{Assessment of GVHD}

Body weights were measured once or twice per week during the entire experimental period. The clinical manifestations of GVHD, including changes in the skin (alopecia, inflamed or scaly skin), generalized signs (fur texture, posture and activity), inflammation of the eyes, and diarrhea, were assessed. Each parameter was quantified with the following scoring system: 0 , normal; 1 , mild; 2 , moderate; and 3, severe (for the scoring of eye inflammation, 4 indicated that both eyes were severely inflamed and closed). The total clinical GVHD scores were defined as the sums of the scores of each parameter. ${ }^{43}$

For the histopathological analyses of the GVHD target tissues, tissue samples were collected from the liver, lung, colon and skin (from the neck) 28 days after DLI and fixed in 10\% formalin. The fixed samples were embedded in paraffin, cut into 5 - $\mu$ m-thick sections, and stained with hematoxylin and eosin (H\&E) for histological examination.

\section{Statistical analysis}

The survival data were analyzed with the log-rank (Mantel-Cox) test using the Prism software (GraphPad Software, Inc., San Diego, CA, USA). The other statistical analyses were performed with Student's $t$-tests using SigmaPlot software (Systat Software, Inc., San Jose, CA, USA).

\section{RESULTS}

CTLA4-CD28 chimera gene modification of T cells increases the GVT effect in a therapeutic model of delayed DLI

To study the effect of delayed DLI on relapsed hematologic malignancies in a murine preclinical model, we set up a wellestablished mixed bone marrow (BM) chimera model using B10.A BM transplantation into irradiated B6 mice. ${ }^{22,42}$ In this model, the recipient $\mathrm{B} 6$ mice were lethally irradiated and subsequently injected with a mix of BM cells from B10.A and 
B6 mice to ensure the uniform generation of mixed chimeras. Next, the mice were left untreated for $\sim 2$ months until the radiation-induced inflammation subsided. To mimic systemic tumor relapse, these mice were intravenously inoculated with EL4 syngeneic B6 T-cell lymphoma cells. Splenocytes from B10.A mice were used as a source of DLI cells. When the B10.A splenocytes were injected 1 week before tumor inoculation, all of the mice survived as previously reported due to efficient tumor elimination by the DLI cells, ${ }^{42}$ whereas the tumor-injected mice without DLI all died within 40 days (Figure 1a). These results indicate that delayed DLI is an efficient prophylactic treatment modality for the prevention of tumor relapse.

Next, we tested whether this effect could be recapitulated in a therapeutic model of tumor relapse. For this purpose, we first inoculated the mixed chimera mice with EL4 cells, and DLI was then performed 4-6 h later on the same day. Surprisingly, no anti-tumor effect of DLI was observed compared with the control mice that were injected with the tumor alone (Figure 1a). Many of the $\mathrm{T}$ cells in the B10.A spleen were naive $\mathrm{T}$ cells that had never encountered $\mathrm{B} 6$ alloantigens. In the preventive model, the 7-day period before tumor inoculation may have provided sufficient time for the naive donor $\mathrm{T}$ cells to be activated by the host alloantigen, which might have facilitated the immediate removal of the tumor cells that were infused by the activated donor $\mathrm{T}$ cells. However, in the therapeutic model, tumor cell seeding and expansion may have surpassed the slow activation of the injected naive donor $\mathrm{T}$ cells. Therefore, we replaced the naive donor splenocytes with donor $\mathrm{T}$ cells that were activated in vitro for several days in the therapeutic model. However, we did not observe an enhanced survival of the recipient mice, which implies that the pre-activation of donor $\mathrm{T}$ cells alone was not sufficient to limit tumor growth (Figure 1b).

We previously reported that CTC28 gene modification of $\mathrm{T}$ cells enhances the therapeutic efficacy of tumor antigen-specific $\mathrm{T}$ cells in autologous $\mathrm{T}$ cell therapy models. ${ }^{36}$ Therefore, we undertook experiments to examine whether CTC28 gene modification of allogeneic donor $\mathrm{T}$ cells would elicit a similar enhancing effect in the therapeutic model of delayed DLI illustrated above. The CTC28 gene-modified donor $\mathrm{T}$ cells were generated by the transduction of $\mathrm{B} 10 . \mathrm{A}$ splenocytes with CTC28 retrovirus and injected into the tumor-bearing recipient mixed chimera mice. Despite this gene modification, the mice did not exhibit any survival benefit (Supplementary Figure 1). During the analysis of the gene-modified $\mathrm{T}$ cell population, we noticed that the CD8 $\mathrm{T}$ cells expanded three- to fourfold more than the $\mathrm{CD} 4 \mathrm{~T}$ cells during the in vitro viral transduction period and thus generated a $\mathrm{CD} 8 \mathrm{~T}$ cell-dominant population (CD4/CD8 ratio of $1: 3$ compared with $1: 1$ in the naive splenocytes). It is well-known that CD4 T cell help is necessary for the optimal tumor-killing effect of CD8 T cells. ${ }^{42,44,45}$ Furthermore, the enhancing effect of CTC28 on T-cell function is far greater in $\mathrm{CD} 4 \mathrm{~T}$ cells than in CD8 $\mathrm{T}$ cells as demonstrated in our previous study. ${ }^{36}$ Therefore, we suspected that the lack of an enhancing effect of the CTC28 T-cell modification might have been due to the relative insufficiency of CD4 T cells in the transduced T-cell population.

To increase the number of the gene-modified CD4 T cells, we purified CD4 and CD8 T cells and separately transduced them with CTC28 retrovirus. High transduction efficiencies for both populations were confirmed by the positivity for the GFP reporter contained in the retroviral vector and by anti-CTLA4 antibody staining (Figure 1c). When we combined the two fractionated populations in a 1:1 ratio and injected them to the tumor-inoculated recipient mice, we observed a substantial enhancement of mouse survival (Figure 1d). Thereafter, we used this mixture of an equal number of fractionated CTC28transduced CD4 and CD8 T cells as the CTC28-transduced DLI cells. Collectively, the CTC28 gene modification of donor $\mathrm{T}$ cells with CD4 $\mathrm{T}$ cell enrichment significantly increased the GVT effect in the therapeutic model of delayed DLI.

\section{Dual modification of CD4 and CD8 T cells is required for the expansion of CD8 $\mathrm{T}$ cells and the GVT effect}

Because we observed that CD4 T cell enrichment enhanced the GVT effect, we sought to evaluate the relative contributions of the CTC28 gene modifications of the CD4 and CD8 T cells in the delayed DLI treatment model. Although the GVT effect of the gene modification of both the CD4 and CD8 T cells was reproduced, the modifications of either the CD4 or CD8 T cells alone did not result in any increase in the survival of the treated mice. Thus, the modification of both populations was critical for the therapeutic effect in this model (Figure 2a).

To understand underlying mechanisms of the therapeutic effect of CTC28-transduced DLI, we first analyzed the in vivo fates of injected DLI cells by tracing the GFP-expressing transduced $\mathrm{T}$ cells in the peripheral blood. The CTC28-transduced CD4 T cells progressively expanded irrespective of the CD8 T-cell modification, whereas the empty vector-transduced $\mathrm{CD} 4 \mathrm{~T}$ cells did not expand in any case (Figures $2 \mathrm{~b}$ and $\mathrm{c}$ ). In contrast, the CTC28-transduced CD8 T cells only expanded in the presence of CTC28transduced $\mathrm{CD} 4 \mathrm{~T}$ cells, which implied that the expansion of CD8 T cells depended on the dual modification of the CD4 and CD8 T cells (Figures 2d and e).

The necessity of dual modification for CD8 T cell expansion correlated with the essentialness of the dual modification for the therapeutic effect, which suggested that the therapeutic effect of this modified DLI might be mediated by the expanded CD8 T cells. To test this possibility, we depleted CD8 T cells in vivo using an anti-CD8 antibody in this modified DLI model. As expected, CD8 depletion abrogated the survival gain from DLI (Figure 3). Thus, CD8 T-cell expansion mediated by dual modification seems to play a primary role in CTC28-transduced DLI-induced GVT effect.

\section{The functional activity of CTC28-transduced T cells is enhanced after in vivo expansion}

Next, we evaluated the effect of CTC28-transduction on the functional activity of expanded DLI cells in vivo. The empty 

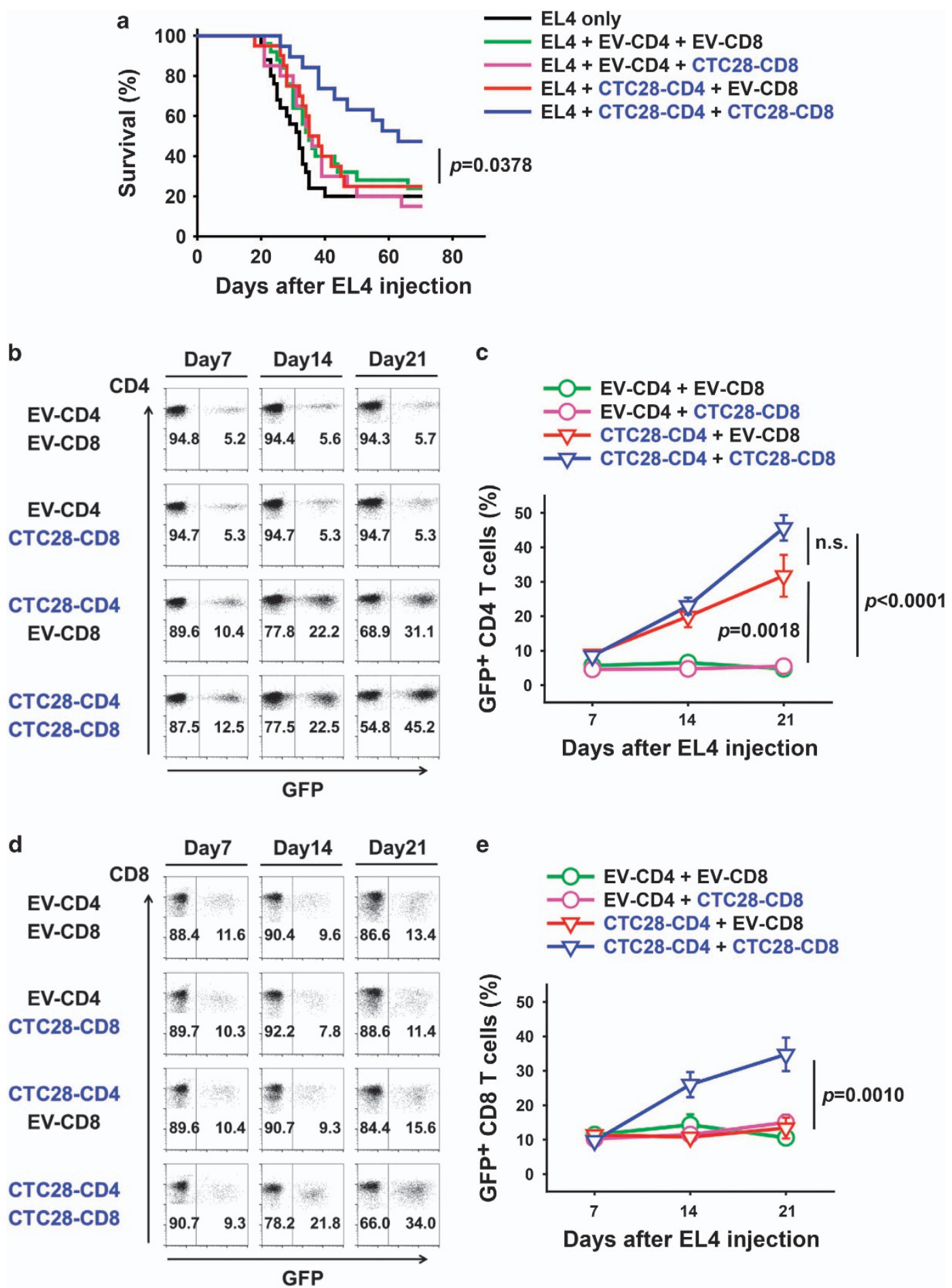

Days after EL4 injection

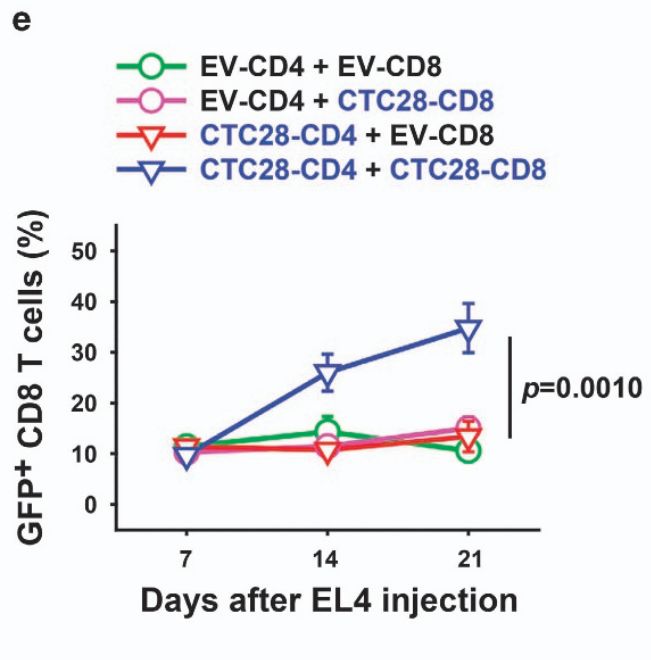

Figure 2 Dual modification of CD4 and CD8 T cells is necessary for the in vivo expansion of CD8 T cells. CD4 and CD8 T cells that were purified from B10.A mice were stimulated with anti-CD3 and anti-CD28 and transduced with either EV or CTC28 retroviruses. After resting, various combinations of EV - or CTC28-transduced CD4 and CD8 T cells were mixed at a 1:1 ratio and i.v. injected into the mixed chimera mice $4-6 \mathrm{~h}$ after EL4 injection. (a) The survival of the mice was compared between the groups ( $P$-value: EL4+CTC28-CD4 +CTC28-CD8 vs EL4+EV-CD4+EV-CD8, log-rank (Mantel-Cox) test). Pooled data from three independent experiments using five mice per group are shown. (b-d) Peripheral blood samples were collected at 7, 14 or 21 days after DLI, and the in vivo expansions of the transduced CD4 T cells $\left(\mathrm{CD}^{+} \mathrm{GFP}^{+}\right)(\mathbf{b}$ and $\mathbf{c})$ and CD8 T cells $\left(\mathrm{CD} 8^{+} \mathrm{GFP}^{+}\right)(\mathbf{d}$ and $\mathbf{e})$ were analyzed by flow cytometry. Representative flow cytometry profiles are presented in ( $b$ and $\mathbf{d}$ ). The percentages of the populations were calculated from the pooled data of two independent experiments using five mice per group and are presented in (c and e). $P$-values: each group vs EV-CD4+EV-CD8, Student's $t$-test; n.s., not significant; error bars, s.e.m. 


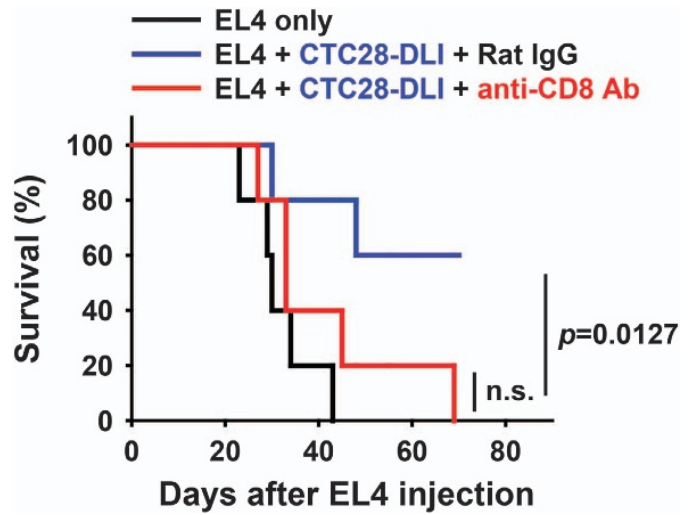

Figure 3 CD8 T cells are responsible for the GVT effect in the therapeutic model of delayed DLI. The combined CTC28transduced CD4 and CD8 T cells were i.v. administered to the mixed chimera mice $4-6 \mathrm{~h}$ after EL4 injection. CD8 T cell depletion was performed by i.v. injecting anti-CD8 antibody into the mice periodically ( $P$-value: compared with EL4 only). A group of mice was injected with normal rat IgG as a negative control (n.s. in comparison with EL4 only). The data were pooled from two independent experiments using five mice per group. $P$-values, log-rank (Mantel-Cox) test.

vector- and CTC28-transduced $\mathrm{T}$ cells that were generated in vitro exhibited similar IFN- $\boldsymbol{\gamma}$-producing capabilities as determined by intracellular cytokine staining following PMA and ionomycin stimulation (Figure 4a). In contrast, when these modified $\mathrm{T}$ cells were isolated from the mice 10-11 days after DLI and stimulated ex vivo with PMA and ionomycin, the percentages of IFN- $\gamma$-producing CD4 and CD8 T cells in the CTC28-transduced population were significantly higher than those in the empty vector-transduced population (Figures $4 \mathrm{~b}-\mathrm{d}$ ). In addition, the IFN- $\gamma$-producing capabilities of the individual DLI cells, as determined by the mean fluorescence intensity (MFI), was also significantly higher in the CTC28-transduced T cells than in the empty vector-transduced cells (Figures $4 \mathrm{~b}$, e and f). Consistently, the blood chimerism of the mice that received CTC28-transduced DLI cells gradually shifted to the donor type (Figures 5a-f). This shift was not due only to the peripheral expansion of the infused donor $\mathrm{T}$ cells but also to the change in hematopoietic stem cell composition because the $\mathrm{B}$ cell composition also shifted to the donor type (Figures $5 \mathrm{e}$ and $\mathrm{f}$ ). This finding implies that the gene-modified donor $\mathrm{T}$ cells enhanced the elimination of the host BM cells due to increased cytotoxicity. Collectively, the improvement of the GVT effect by the CTC28 transduction of DLI cells correlated with the quantitative increase in alloreactive $\mathrm{T}$ cells that was followed by enhanced effector function in vivo.

\section{CTC28-transduced DLI is accompanied by late-onset and non-lethal GVHD}

Although the tumor-bearing mixed chimera mice that were treated with the modified DLI survived longer than the untreated control mice, their gross appearance differed from that typically observed in mice treated with preventive DLI.
Hunched postures, erupted hairs and low mobility suggested that the mice were experiencing some degree of GVHD. Although delayed DLI is not usually accompanied by GVHD, the increased functionality of the CTC28-transduced T cells may have provoked GVHD-inducing capacity. However, it was difficult to ascribe the morbidity of the mice to T-cell-mediated GVHD because the tumor burden itself could have caused morbidity in the mice.

To exclude the role of tumor cells in GVHD development, we transferred these modified $\mathrm{T}$ cells into mixed chimeric mice without tumor injection and monitored the clinical manifestations of the mice. In the empty vector-transduced DLI group, body weight loss and clinical GVHD symptoms were not observed during the experimental period. In contrast, the CTC28-transduced DLI-treated mice began to lose their body weight 7 days after DLI and gradually lost $\sim 25 \%$ of their initial body weight by $\sim 40$ days after DLI (Figure 6a). The clinical GVHD scores also progressively increased after DLI (Figure 6b). When several GVHD target organs were isolated and histologically examined 28 days after DLI, a moderate increase in lymphocyte infiltration into the tissues was observed in the CTC28-transduced DLI group compared with the empty vector-transduced group and the group without DLI (Figure $6 \mathrm{c}$ ). Nonetheless, no mice died of GVHD during the 75-day of experimental period, which differentiated this condition from the acute lethal GVHD that is typically observed in allogeneic DLI settings.

\section{IL-10-transduced third-party MSCs mitigate GVHD and enhance survival}

The CTC28-transduced DLI-mediated GVHD was not lethal in the tumor-free conditions. However, its negative influence on the survival of the tumor-bearing mice cannot be excluded because a significant percentage $(30-60 \%)$ of the mice that were treated with the gene-modified DLI still eventually died. Therefore, we searched for an additional treatment to mitigate the GVHD without impairing the GVT effect of the CTC28-transduced DLI. Several strategies using either FTY720, which is a reagent for blocking the egress of $\mathrm{T}$ cells from the lymphoid organs, or the co-modification of $\mathrm{T}$ cells with suicidal genes, such as herpes simplex virus thymidine kinase or inducible caspase 9 were not successful in our hands (data not shown). Finally, we decided to test the GVHDsuppressing capability of mesenchymal stem cells (MSCs) in our model. MSCs have been reported to suppress acute GVHD in pre-clinical models and clinical trials. ${ }^{46-48}$ Due to their immunosuppressive nature, allogeneic third-party MSCs have been used in clinical trials. ${ }^{48}$ Therefore, we decided to examine the effect of murine third-party MSCs in our system. The MSC line from Balb/C mice (D3116) was established by a sub-fractionation culturing method. ${ }^{40}$ The MSCs were intraperitoneally injected weekly three times beginning on the day of the DLI in our CTC28-transduced DLI model. Disappointingly, this treatment did not elicit any GVHD-alleviating effect or any effect on mouse survival (Supplementary Figure 2). However, there are some studies 

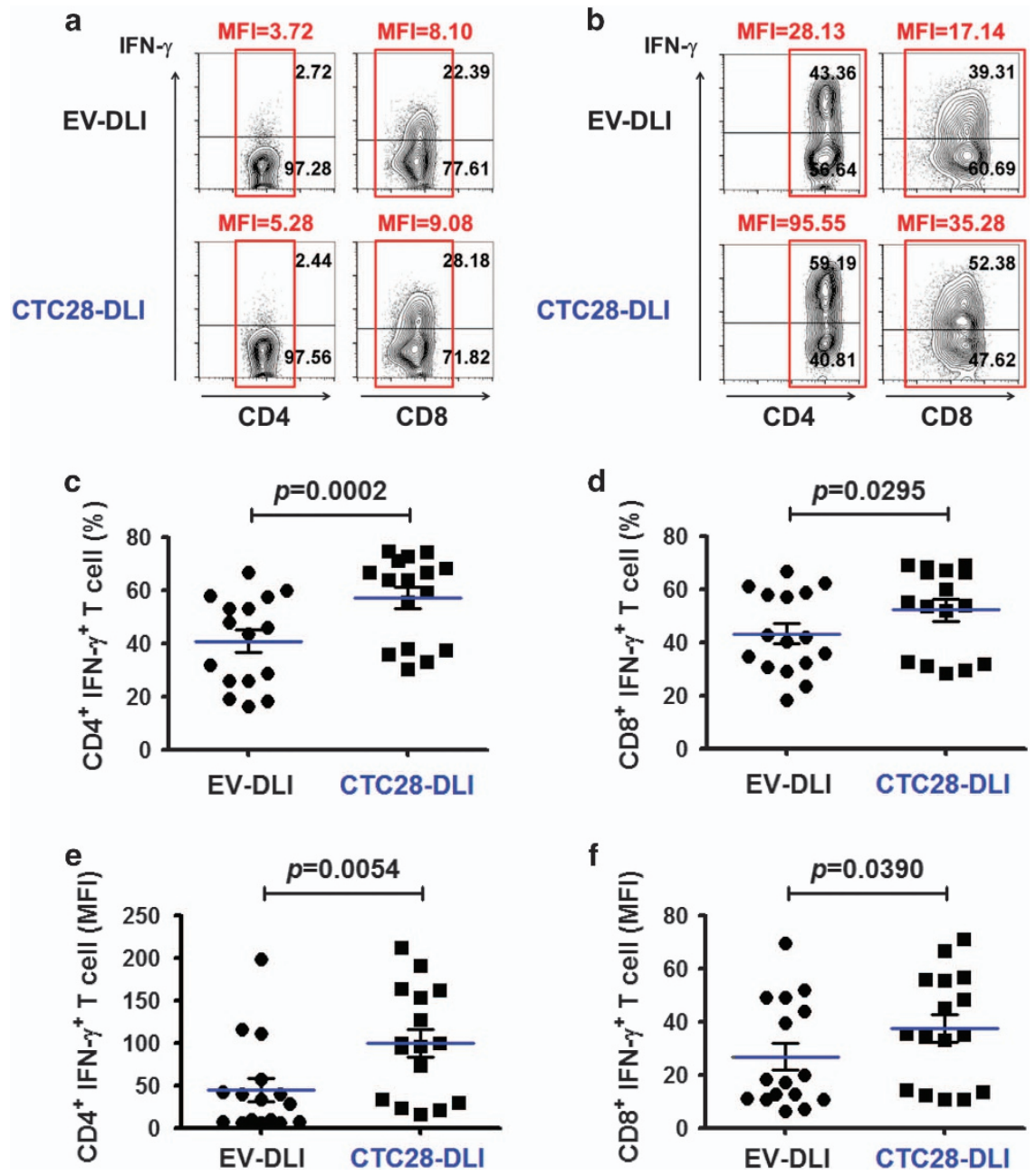

Figure 4 The functional activity of the CTC28-transduced T cells is enhanced after in vivo expansion. CTC28-transduced or EV-transduced CD4 and CD8 T cells were generated and introduced into EL4 tumor-bearing mixed chimera mice as in Figure 1d. (a and b) The transduced T cells prior to DLI (a) and splenocytes isolated 10 days after DLI (b) were stimulated with PMA and ionomycin for $4 \mathrm{~h}$, and IFN- $\gamma$ production was analyzed by intracellular staining via flow cytometry. Representative flow cytometry profiles of GFP-positive cells (the transduced T cells) are shown. (c-f) For the GFP-positive T cells that were isolated and stimulated as in (b), the percentages of IFN- $\gamma$ producing cells (c and $\mathbf{d}$ ) and the mean fluorescent intensities (MFIs) of the produced IFN- $\gamma$ (e and $\mathbf{f}$ ) were quantified from pooled data from four independent experiments using three to five mice per group. $P$-values, Student's $t$-test.

that have demonstrated that unmodified MSCs have limited anti-GVHD effects, whereas genetically modified MSCs suppress GVHD. ${ }^{49,50}$ In one report, IL10-overexpressing MSCs exhibited a protective effect against GVHD in an allogeneic BM transplantation model. ${ }^{41}$ Therefore, we generated IL10-overexpressing D3116 MSCs via the retroviral transduction of IL-10 cDNA. IL-10 overexpression was confirmed by the increased secretion of IL-10 into the culture supernatant compared with that from the empty vector-transduced MSCs as measured by ELISA (Figure 7a).

Next, we checked the protective effects of these cells against GVHD in the CTC28-transduced DLI model. All groups of mice, including the mice that were injected with tumors alone, those treated with the modified DLI, and those treated with the modified DLI and IL-10-transduced MSCs, exhibited similar low-grade weight loss and GVHD by $\sim 30$ days after DLI (Figures $7 b$ and c). Thereafter, many mice in the tumor-alone group and the DLI-treated group began to die, which hampered the measurement of the GVHD scores for those groups. Surprisingly however, we found that the overall survival of the mice in IL-10-transduced MSCs-treated group was greatly enhanced compared with the DLI-treated group without MSCs (Figure 7d). Accordingly, we were able to measure the degree of GVHD in the MSC-treated group at $\sim 70$ days after DLI. At this time, the GVHD score was maintained at very low levels (Figure 7c). Moreover, the mice in the MSC-treated group did not lose further body weight and exhibited a slight recovery at this time point (Figure $7 \mathrm{~b}$ ). The degrees of GVHD and weight loss in the MSC-treated group at approximately day 70 after DLI were far lower than those of the DLI-treated mice without tumor injection at a similar time point as illustrated in Figures $6 \mathrm{a}$ and $\mathrm{b}$ (GVHD score: $<0.5$ versus 7; weight loss: $10 \%$ versus $25 \%$ ). In summary, IL10-transduced third-party MSCs inhibited 
a

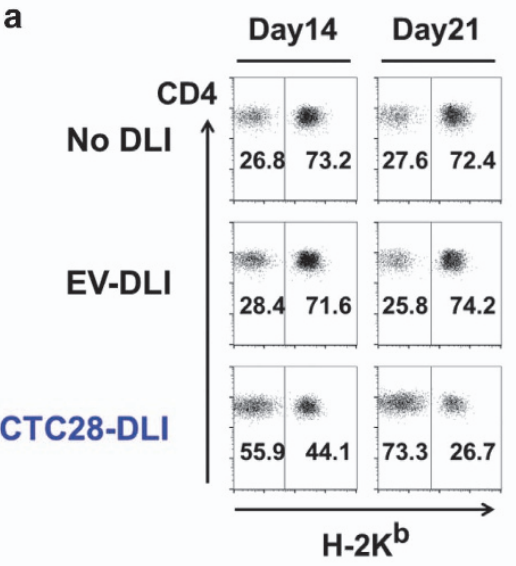

C

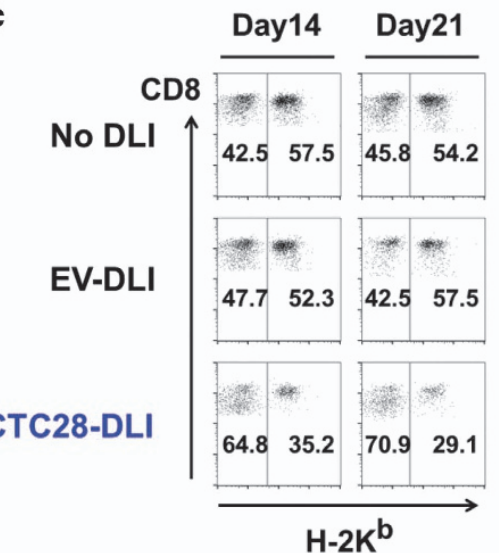

e

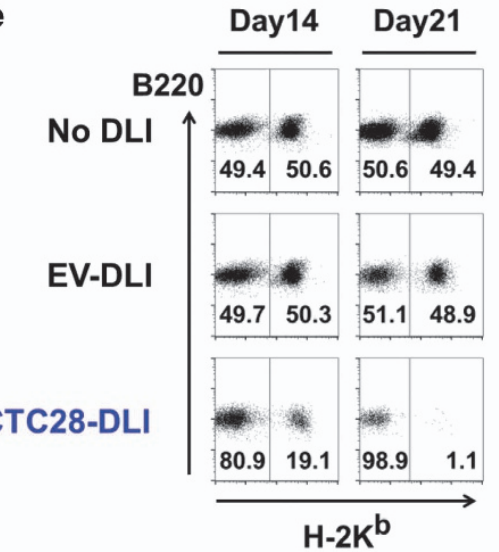

b
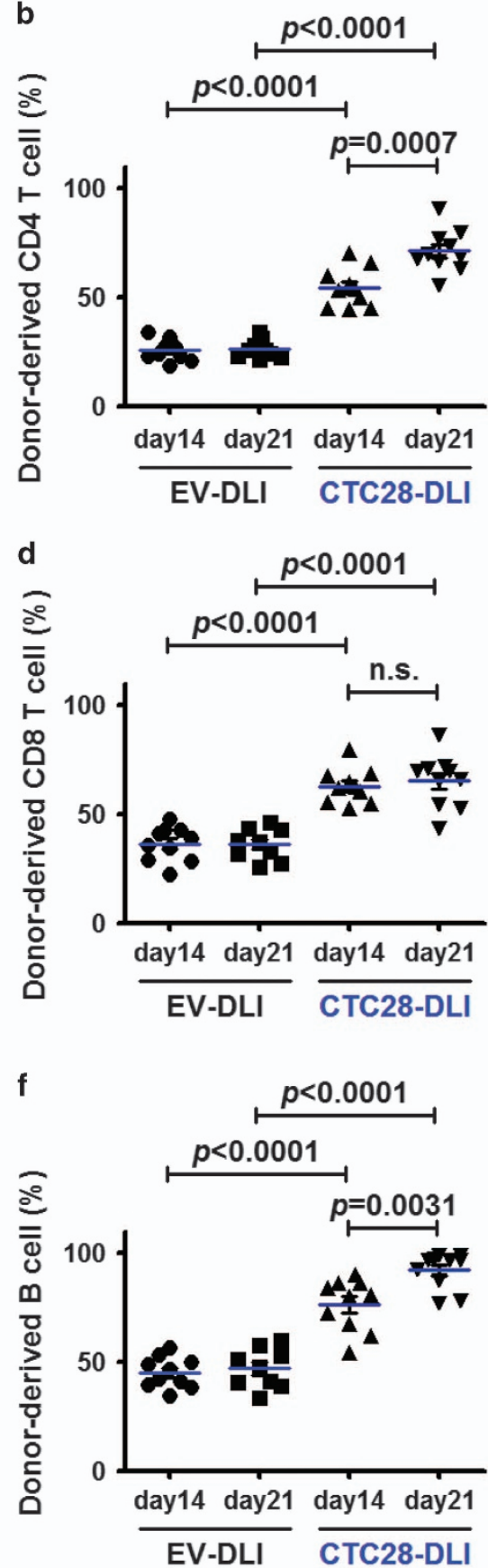

Figure 5 Mixed chimerism in the peripheral blood shifts to the donor type following CTC28-transduced DLI. The proportions of blood cells that originated from the donor and host hematopoietic cells (mixed chimerism) were assessed periodically after CTC28 - or EV-transduced DLI into EL4-tumor bearing mixed chimera mice as in Figure $1 \mathrm{~d}$. The percentages of $\mathrm{H}-2 \mathrm{~K}^{\mathrm{b}}$-positive (host-derived) and $\mathrm{H}-2 \mathrm{~K}^{\mathrm{b}}$-negative (donor-derived) cells in the CD4- (a and $\mathbf{b}), \mathrm{CD} 8-(\mathbf{c}$ and $\mathbf{d})$ and B220-positive cells (e and $\mathbf{f}$ ) were analyzed via flow cytometry. Representative flow cytometry profiles 14 and 21 days after DLI are shown in (a, $\mathbf{c}$ and $\mathbf{e}$ ). The percentages of donor-derived cells were analyzed using pooled data from two independent experiments using five mice per group in (b, $\mathbf{d}$ and $\mathbf{f}$ ). $P$-values, Student's $t$-test.

the modified DLI-mediated GVHD without hampering the GVT effect. Furthermore, the administration of the MSCs increased the survival of the DLI-infused mice. Thus, the combination of CTC28-transduced DLI and IL-10-transduced MSC therapy could be a useful strategy for the treatment of tumor relapse after HSCT with reduced intensity conditioning.

\section{DISCUSSION}

Anti-tumor T-cell therapy has recently gained much attention. $^{51}$ Specifically, $\mathrm{T}$-cell therapies for hematologic malignancies are rapidly growing because antigen-specific T-cell therapies for EBV-positive lymphomas and chimeric antigen receptor-transduced T-cell therapies against CD19positive hematologic tumors have been very successful in 

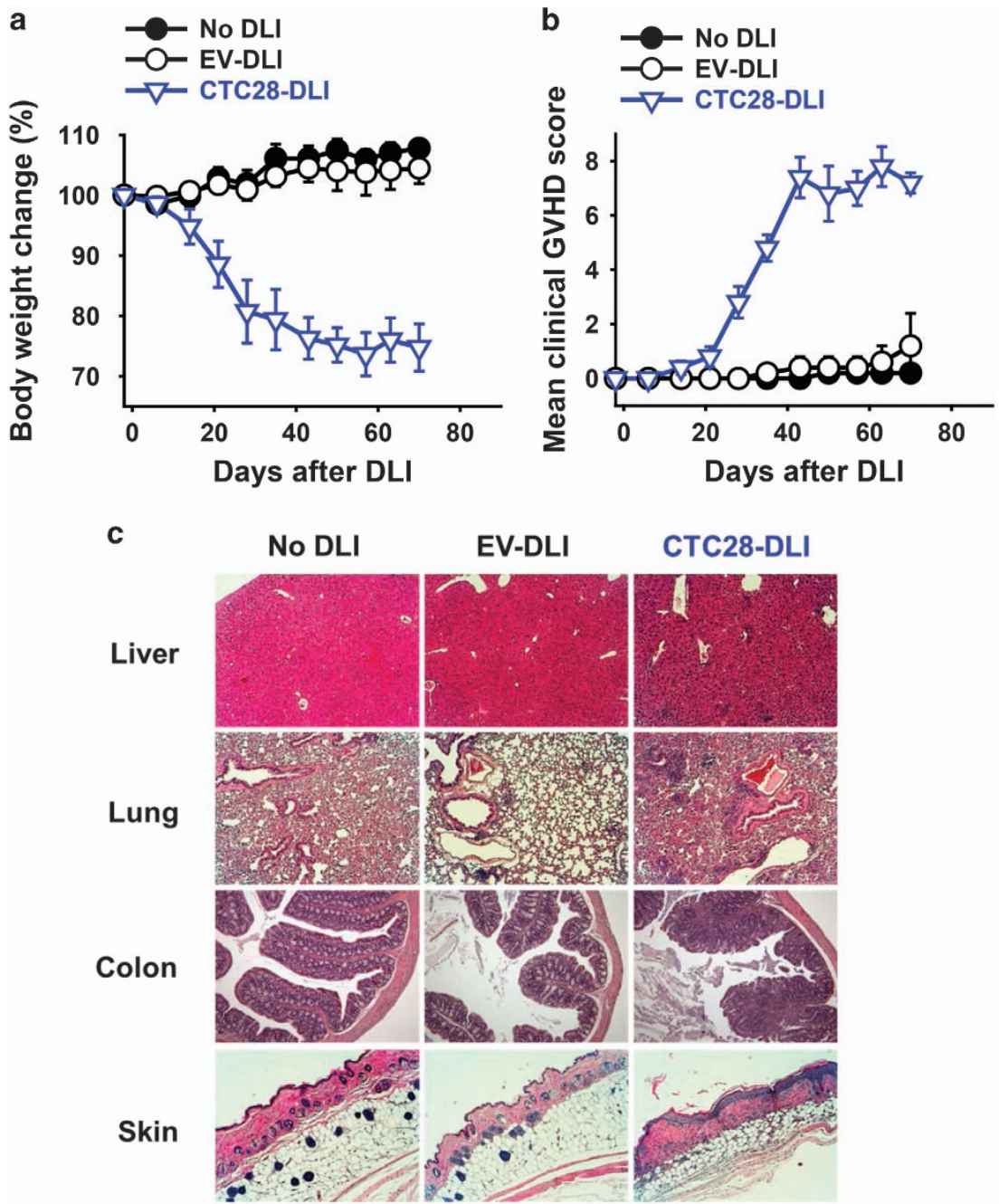

Figure 6 CTC28-transduced DLI induces late-onset and non-lethal GVHD. CTC28- and EV-transduced DLI were performed in the mixed chimera mice without EL4 tumor injection. A group of the mice did not receive donor lymphocytes (No DLI) as a negative control. (a and $\mathbf{b}$ ) The degree of GVHD was assessed periodically by weight loss (a) and clinical scoring for GVHD (b) over 70 days. (c) The main tissues involved in GVHD were isolated 28 days after DLI, and tissue sections were stained with hematoxylin and eosin for histological examination. The results are representative of two independent experiments. The error bars indicate the s.e.m.

clinical trials. ${ }^{52,53}$ These treatments are usually based on the expansion or gene modification of autologous $\mathrm{T}$ cells from patients with advanced tumors, which may not always be feasible. Allogeneic T-cell therapy against alloantigens will have some advantages over autologous $\mathrm{T}$-cell therapy because polyclonal allogeneic $\mathrm{T}$ cells target multiple antigens rather than a single antigen, and they can be obtained from healthy donors. DLI is a form of allogeneic T-cell therapy that accompanies HSCT and has been used in daily clinical practice. Thus, enhancing the efficacy of DLI will be easily translated into the clinic if the procedures are properly designed. In this study, we demonstrated that CTC28, a mutant of CTLA4 that has previously been used to enhance the efficacy of autologous T-cell therapy, can also be used to increase the efficacy of DLI in an HSCT setting.

The mouse model we used in this study mimics tumor relapse after HSCT accompanied by reduced intensity conditioning. Specifically, EL4 cells exhibited an aggressive
ALL-like behavior as demonstrated by the finding that the intravenous injection of only $1 \times 10^{4}$ tumor cells into mice was sufficient to induce lethality within 40 days. Similarly, conventional DLI can only prevent tumor seeding and but cannot limit the growth of pre-existing tumor cells in mice. Thus, it is a good model for attempts to enhance the efficacy of DLI against poorly responsive relapsed ALL. Delayed DLI in this model is also similar to clinical DLI settings because DLI is typically performed several months after HSCT to prevent or treat tumor relapse in clinical practice. ${ }^{23}$

The main finding of this report is that CTC28-transduced DLI was able to enhance the survival of the mixed chimera mice in a therapeutic model in which conventional DLI did not elicit any survival gain. There are several intriguing observations. While the CD8 T-cell-dominant unfractionated gene-modified population did not exhibit any therapeutic effect, increasing the proportion of $\mathrm{CD} 4 \mathrm{~T}$ cells via the separate gene modification of CD4 and CD8 T cells and subsequent 
a

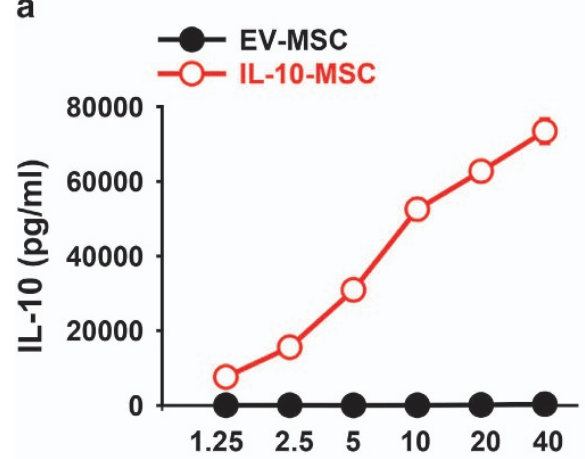

Number of MSCs $\left(\times 10^{3}\right)$

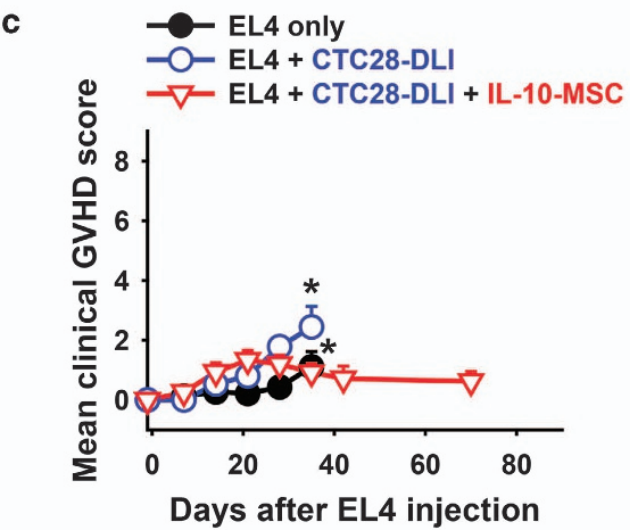

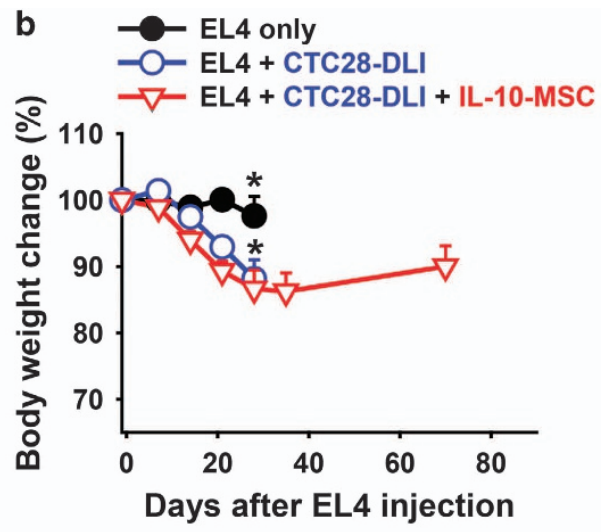

d

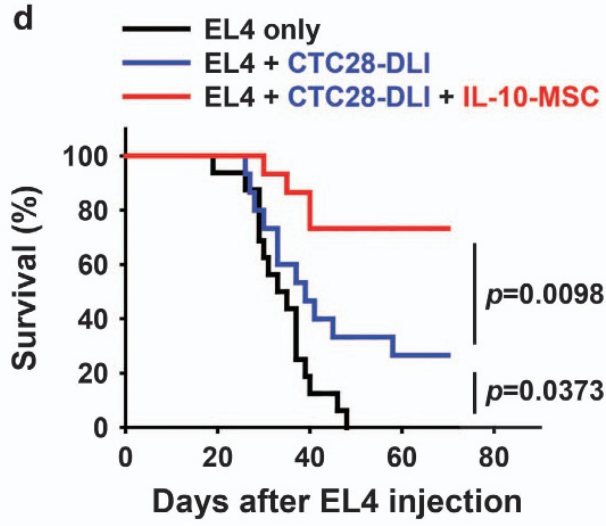

Figure 7 IL-10-transduced third-party MSCs mitigate DLI-induced GVHD and enhance mouse survival in the tumor-bearing mixed chimeras. (a) IL-10 - and EV-transduced D3116 BALB/C MSCs (IL-10-MSC; EV-MSC) were generated by retroviral transduction. The amounts of IL-10 produced by various numbers of MSCs were measured in the $48 \mathrm{~h}$ culture supernatant by ELISA. (b-d) CTC28- and EV-transduced DLI were performed in the tumor-bearing mixed chimera mice as in Figure 1d. IL-10-MSCs were i.p. administered three times at 7-day intervals beginning on the day of tumor injection/DLI. The degree of GVHD was assessed by weight loss (b) and clinical scoring (c). The survival of the mice was periodically monitored (d). * , for the groups treated with tumor alone and with tumor plus DLI, the GVHD assessments were halted at 28-35 days after DLI due to the significant deaths of the tumor-bearing mice. The data were pooled from three independent experiments using five mice per group. $P$-values, log-rank (Mantel-Cox) test.

mixing of these cells elicited a therapeutic benefit. The importance of CD4 $\mathrm{T}$ cells in this model was demonstrated in our previous report in which CD4 T cell-depleted DLI lost its GVT effect in a preventive naive DLI setting. ${ }^{42}$ However, a simple increase in the CD4 $\mathrm{T}$ cell proportion in the DLI population without CTC28 gene modification did not elicit a therapeutic effect in our model (that is, the empty vector-transduced DLI). A sufficient proportion of CTC28transduced CD4 $\mathrm{T}$ cells had to be provided for the anti-tumor effect. This observation is consistent with our previous study on autologous T cell therapy models in which CTC28 gene modification of CD4 $\mathrm{T}$ cells was found to be essential for tumor regression. ${ }^{36}$

The peculiarity of this model is that the CTC28 gene modification of CD8 T cells was absolutely necessary for the GVT effect. In our previous models, although the modification of CD8 $\mathrm{T}$ cells further enhanced tumor regression, the modification of CD4 $\mathrm{T}$ cells alone was sufficient to mediate an anti-tumor effect, which was consistent with the observation that CTLA4-deficiency enhanced the activation of CD4 T cells to a greater extent than CD8 T cells. ${ }^{36,54}$ The necessity of
CD8 $\mathrm{T}$ cell modification in the current model was clearly demonstrated by the finding that the CD8 T cells expanded only in the dual modification condition. The reason for this difference is currently not known. However, the following points merits discussion. In the previous model, all of the CD8 $\mathrm{T}$ cells were tumor antigen-specific $\mathrm{T}$ cells that could immediately recognize tumor cells. In the present model, only $1-10 \%$ of the $\mathrm{T}$ cells were alloreactive $\mathrm{T}$ cells that need to be expanded to execute their cytotoxic function. Thus, the CD8 $\mathrm{T}$ cells may have required additional autologous help from the CTC28 gene modification to increase their survival and expansion. In support of this idea, autocrine IL-2 secreted by CD8 T cells is known to be necessary for memory CD8 $\mathrm{T}$ cell generation. ${ }^{55}$ Alternately, in the previous model, large subcutaneous tumors had been pre-established by the time the $\mathrm{T}$ cells were administered. ${ }^{36}$ In contrast, in the present model, only a small number of circulating tumor cells were present in the blood at the time of T cell administration, which limited access to sufficient target antigens. Thus, an additional gene modification may have been needed to drive sufficient CD8 T-cell expansion. 
The delayed DLI in the preventive model of tumor relapse demonstrated that the GVT effect could be selectively induced without GVHD. ${ }^{42}$ However, in the therapeutic model, the CTC28-transduced DLI-mediated GVT effect was accompanied by GVHD. Although radiation-induced inflammation was reduced in the 2-month period after HSCT, potentiation of the donor $\mathrm{T}$ cells via CTC28 modification might have inevitably caused tissue infiltration by these T cells. In CTLA4 knockout mice, CTLA4-deficient $\mathrm{T}$ cells hyperproliferate and infiltrate various tissues, which leads to autoimmune lethality within 3-4 weeks of birth. ${ }^{54,56}$ In the present study, alloreactive CTC28-DLI cells acted similarly to CTLA4-deficient $\mathrm{T}$ cells by exhibiting hyperproliferation and tissue infiltration that led to GVHD. However, the DLI-induced GVHD was delayed-onset, moderate and non-lethal, which contrasts with the aggressive early lethality that is typically observed in acute GVHD. This difference may have resulted from the greater time required for the transferred DLI cells to expand to the level needed for tissue infiltration in the absence of inflammation. Nonetheless, controlling this unwanted side effect is necessary for the potential application of this approach.

MSCs have been reported to attenuate GVHD without impairing the GVT effect in both experimental settings and clinical trials. ${ }^{57,58}$ MSCs are nonhematopoietic multipotent adult progenitor cells that can differentiate into a variety of cell types and have been reported to suppress the immune response in many disease processes including GVHD. ${ }^{59}$ Although the early phase clinical trials for GVHD have shown promise, ${ }^{32,60,61}$ a large scale phase III clinical trial (http://investor.osiris.com/releasedetail.cfm?ReleaseID = 407404) failed to demonstrate a clinical benefit for allogeneic MSCs. We were also unable to observe any effect of allogeneic third-party MSCs in our murine model. This inconsistency may be due to unstandardized methods of cell isolation and culture. Although the immunomodulatory mechanisms of MSCs are not fully elucidated, immunosuppression is mainly mediated by soluble factors that include transforming growth factor- $\beta 1$ (TGF- $\beta 1),{ }^{62,63}$ prostaglandin E2 (PGE2), ${ }^{64}$ indoleamine-pyrrole 2,3-dioxygenase (IDO) ${ }^{65,66}$ and interleukin-10 (IL-10). ${ }^{67,68}$ Specifically, IL-10 gene-modified MSCs have been reported to potentiate the immunomodulatory effect against acute GVHD in an experimental allogeneic HSCT model. ${ }^{41}$ When we tested IL-10 gene-modified MSCs in our model, we observe an attenuation of GVHD with the maintenance, or rather enhancement, of the GVT effect. This separation of the GVT effect and GVHD may have been due to the preferential migration of MSCs to the inflammatory tissues and the subsequent local secretion of immunosuppressive IL-10. ${ }^{69}$ The enhanced survival of the mice that were treated with IL-10-transduced MSCs compared with the survival of the mice that were treated with DLI alone implies that some mice may have died due to GVHD and not due to the tumors in the DLI-treated group, and the IL-10-transduced MSCs may have rescued these mice. This possibility needs to be analyzed in greater detail in the future.

Overall, the CTC28 gene modification of allogeneic T cells was able to enhance the efficacy of DLI in the mixed chimera after HSCT. This finding is another example of the usefulness of this mutant receptor in $\mathrm{T}$ cell-based treatment. However, the overall enhancement of $\mathrm{T}$ cell function necessitates another tool to regulate the accompanying GVHD. IL-10-overexpressing MSCs can effectively supplement CTC28-mediated T-cell therapy by reducing GVHD and potentiating the GVT effect, which demonstrated the potential of genetically modified cell therapies in the treatment of tumors.

\section{CONFLICT OF INTEREST}

The authors declare no conflict of interest.

\section{ACKNOWLEDGEMENTS}

We thank Drs Il-Hoan Oh and Sun U Song for providing us with valuable materials. We are also grateful to Su-Hyung Lee (National Cancer Center) for reviewing the histology slides. This work was supported by grants from the National Cancer Center (NCC-1610371) and the Bio \& Medical Technology Development Program of the National Research Foundation (NRF) funded by the Korean government, MSIP (NRF-2016M3A9D3900438), Republic of Korea.

1 Jenq RR, van den Brink MR. Allogeneic haematopoietic stem cell transplantation: individualized stem cell and immune therapy of cancer. Nat Rev Cancer 2010; 10: 213-221.

2 Li HW, Sykes M. Emerging concepts in haematopoietic cell transplantation. Nat Rev Immunol 2012; 12: 403-416.

3 Hill GR, Crawford JM, Cooke KR, Brinson YS, Pan L, Ferrara JL. Total body irradiation and acute graft-versus-host disease: the role of gastrointestinal damage and inflammatory cytokines. Blood 1997; 90: 3204-3213.

4 Spitzer TR, McAfee S, Sackstein R, Colby C, Toh HC, Multani P et al. Intentional induction of mixed chimerism and achievement of antitumor responses after nonmyeloablative conditioning therapy and HLA-matched donor bone marrow transplantation for refractory hematologic malignancies. Biol Blood Marrow Transplant 2000; 6(3A): 309-320.

5 Liu H, Rich ES, Godley L, Odenike O, Joseph L, Marino S et al. Reducedintensity conditioning with combined haploidentical and cord blood transplantation results in rapid engraftment, low GVHD, and durable remissions. Blood 2011; 118: 6438-6445.

6 Kohrt HE, Turnbull BB, Heydari K, Shizuru JA, Laport GG, Miklos DB et al. TLI and ATG conditioning with low risk of graft-versus-host disease retains antitumor reactions after allogeneic hematopoietic cell transplantation from related and unrelated donors. Blood 2009; 114: 1099-1109.

7 Horowitz MM, Gale RP, Sondel PM, Goldman JM, Kersey J, Kolb HJ et al. Graft-versus-leukemia reactions after bone marrow transplantation. Blood 1990; 75: 555-562.

8 Bensinger WI. The current status of reduced-intensity allogeneic hematopoietic stem cell transplantation for multiple myeloma. Leukemia 2006; 20: 1683-1689.

9 Alyea EP, DeAngelo DJ, Moldrem J, Pagel JM, Przepiorka D, Sadelin M et al. $\mathrm{NCl}$ First International Workshop on The Biology, Prevention and Treatment of Relapse after Allogeneic Hematopoietic Cell Transplantation: report from the committee on prevention of relapse following allogeneic cell transplantation for hematologic malignancies. Biol Blood Marrow Transplant 2010; 16: 1037-1069.

10 Kolb HJ, Mittermuller J, Clemm C, Holler E, Ledderose G, Brehm G et al. Donor leukocyte transfusions for treatment of recurrent chronic myelogenous leukemia in marrow transplant patients. Blood 1990; 76: 2462-2465.

11 Collins RH Jr., Shpilberg O, Drobyski WR, Porter DL, Giralt S, Champlin R et al. Donor leukocyte infusions in 140 patients with relapsed malignancy after allogeneic bone marrow transplantation. J Clin Oncol 1997; 15: 433-444. 
12 Roddie C, Peggs KS. Donor lymphocyte infusion following allogeneic hematopoietic stem cell transplantation. Expert Opin Biol Ther 2011; 11: 473-487.

13 Raiola AM, Van Lint MT, Valbonesi M, Lamparelli T, Gualandi F, Occhini D et al. Factors predicting response and graft-versus-host disease after donor lymphocyte infusions: a study on 593 infusions. Bone Marrow Transplant 2003; 31: 687-693.

14 Schmid C, Labopin M, Nagler A, Bornhauser M, Finke J, Fassas A et al. Donor lymphocyte infusion in the treatment of first hematological relapse after allogeneic stem-cell transplantation in adults with acute myeloid leukemia: a retrospective risk factors analysis and comparison with other strategies by the EBMT Acute Leukemia Working Party. J Clin Oncol 2007; 25: 4938-4945.

15 Porter DL, Collins RH Jr., Hardy C, Kernan NA, Drobyski WR, Giralt S et al. Treatment of relapsed leukemia after unrelated donor marrow transplantation with unrelated donor leukocyte infusions. Blood 2000; 95: 1214-1221.

16 Chang X, Zang X, Xia CQ. New strategies of DLI in the management of relapse of hematological malignancies after allogeneic hematopoietic SCT. Bone Marrow Transplant 2016; 51: 324-332.

17 Ferrara JL, Levine JE, Reddy P, Holler E. Graft-versus-host disease. Lancet 2009; 373: 1550-1561.

18 Fowler DH. Shared biology of GVHD and GVT effects: potential methods of separation. Crit Rev Oncol Hematol 2006; 57: 225-244.

19 Hari P, Logan B, Drobyski WR. Temporal discordance between graft-versusleukemia and graft-versus-host responses: a strategy for the separation of graft-versus-leukemia/graft-versus-host reactivity? Biol Blood Marrow Transplant 2004; 10: 743-747.

20 Shlomchik WD. Graft-versus-host disease. Nat Rev Immunol 2007; 7: 340-352.

21 Blazar BR, Murphy WJ, Abedi M. Advances in graft-versus-host disease biology and therapy. Nat Rev Immunol 2012; 12: 443-458.

22 Mapara MY, Kim YM, Wang SP, Bronson R, Sachs DH, Sykes M. Donor lymphocyte infusions mediate superior graft-versus-leukemia effects in mixed compared to fully allogeneic chimeras: a critical role for host antigen-presenting cells. Blood 2002; 100: 1903-1909.

23 Krishnamurthy P, Potter VT, Barber LD, Kulasekararaj AG, Lim ZY, Pearce RM et al. Outcome of donor lymphocyte infusion after $\mathrm{T}$ celldepleted allogeneic hematopoietic stem cell transplantation for acute myelogenous leukemia and myelodysplastic syndromes. Biol Blood Marrow Transplant 2013; 19: 562-568.

24 Kim YM, Sachs T, Asavaroengchai W, Bronson R, Sykes M. Graft-versus-host disease can be separated from graft-versus-lymphoma effects by control of lymphocyte trafficking with FTY720. J Clin Invest 2003; 111: 659-669.

25 Taylor PA, Ehrhardt MJ, Lees CJ, Tolar J, Weigel BJ, Panoskaltsis-Mortari A et al. Insights into the mechanism of FTY720 and compatibility with regulatory $T$ cells for the inhibition of graft-versus-host disease (GVHD). Blood 2007; 110: 3480-3488.

26 Bonini C, Ferrari G, Verzeletti S, Servida P, Zappone E, Ruggieri L et al. HSV-TK gene transfer into donor lymphocytes for control of allogeneic graft-versus-leukemia. Science 1997; 276: 1719-1724.

27 Ciceri F, Bonini C, Marktel S, Zappone E, Servida P, Bernardi M et al. Antitumor effects of HSV-TK-engineered donor lymphocytes after allogeneic stem-cell transplantation. Blood 2007; 109: 4698-4707.

28 Di Stasi A, Tey SK, Dotti G, Fujita Y, Kennedy-Nasser A, Martinez C et al. Inducible apoptosis as a safety switch for adoptive cell therapy. $N$ Engl J Med 2011; 365: 1673-1683.

29 Zhou X, Dotti G, Krance RA, Martinez CA, Naik S, Kamble RT et al. Inducible caspase-9 suicide gene controls adverse effects from alloreplete T cells after haploidentical stem cell transplantation. Blood 2015; 125 : 4103-4113.

30 Brunstein CG, Miller JS, Cao Q, McKenna DH, Hippen KL, Curtsinger J et al. Infusion of ex vivo expanded T regulatory cells in adults transplanted with umbilical cord blood: safety profile and detection kinetics. Blood 2011; 117: 1061-1070.

31 Di lanni M, Falzetti F, Carotti A, Terenzi A, Castellino F, Bonifacio E et al. Tregs prevent GVHD and promote immune reconstitution in HLA-haploidentical transplantation. Blood 2011; 117: 3921-3928.

32 Le Blanc K, Frassoni F, Ball L, Locatelli F, Roelofs H, Lewis I et al. Mesenchymal stem cells for treatment of steroid-resistant, severe, acute graft-versus-host disease: a phase II study. Lancet 2008; 371: 1579-1586.

33 Perez-Simon JA, Lopez-Villar O, Andreu EJ, Rifon J, Muntion S, Diez Campelo $\mathrm{M}$ et al. Mesenchymal stem cells expanded in vitro with human serum for the treatment of acute and chronic graft-versus-host disease: results of a phase I/II clinical trial. Haematologica 2011; 96: 1072-1076.

34 Kershaw MH, Teng MW, Smyth MJ, Darcy PK. Supernatural T cells: genetic modification of T cells for cancer therapy. Nat Rev Immunol 2005; 5: 928-940.

35 Ngo MC, Rooney CM, Howard JM, Heslop HE. Ex vivo gene transfer for improved adoptive immunotherapy of cancer. Hum Mol Genet 2011; 20 (R1): R93-R99.

36 Shin JH, Park HB, Oh YM, Lim DP, Lee JE, Seo HH et al. Positive conversion of negative signaling of CTLA4 potentiates antitumor efficacy of adoptive T-cell therapy in murine tumor models. Blood 2012; 119: 5678-5687.

37 Peggs KS, Quezada SA, Allison JP. Cell intrinsic mechanisms of T-cell inhibition and application to cancer therapy. Immunol Rev 2008; 224: $141-165$.

38 Leach DR, Krummel MF, Allison JP. Enhancement of antitumor immunity by CTLA-4 blockade. Science 1996; 271: 1734-1736.

39 Robert C, Thomas L, Bondarenko I, O'Day S, Weber J, Garbe C et al. Ipilimumab plus dacarbazine for previously untreated metastatic melanoma. N Engl J Med 2011; 364: 2517-2526.

40 Jeon MS, Yi TG, Lim HJ, Moon SH, Lee MH, Kang JS et al. Characterization of mouse clonal mesenchymal stem cell lines established by subfractionation culturing method. World J Stem Cells 2011; 3: 70-82.

41 Min CK, Kim BG, Park G, Cho B, Oh IH. IL-10-transduced bone marrow mesenchymal stem cells can attenuate the severity of acute graft-versushost disease after experimental allogeneic stem cell transplantation. Bone Marrow Transplant 2007; 39: 637-645.

42 Chakraverty R, Eom HS, Sachs J, Buchli J, Cotter P, Hsu R et al. Host MHC class II+ antigen-presenting cells and CD4 cells are required for CD8-mediated graft-versus-leukemia responses following delayed donor leukocyte infusions. Blood 2006; 108: 2106-2113.

43 Li HW, Sachs J, Pichardo C, Bronson R, Zhao G, Sykes M. Nonalloreactive $T$ cells prevent donor lymphocyte infusion-induced graft-versus-host disease by controlling microbial stimuli. J Immunol 2012; 189: 5572-5581.

$44 \mathrm{Hu}$ HM, Winter H, Urba WJ, Fox BA. Divergent roles for CD4+ T cells in the priming and effector/memory phases of adoptive immunotherapy. J Immunol 2000; 165: 4246-4253.

45 Baxevanis CN, Voutsas IF, Tsitsilonis OE, Gritzapis AD, Sotiriadou R, Papamichail M. Tumor-specific CD4+ T lymphocytes from cancer patients are required for optimal induction of cytotoxic $T$ cells against the autologous tumor. J Immunol 2000; 164: 3902-3912.

46 Ren G, Zhang L, Zhao X, Xu G, Zhang Y, Roberts Al et al. Mesenchymal stem cell-mediated immunosuppression occurs via concerted action of chemokines and nitric oxide. Cell Stem Cell 2008; 2: 141-150.

47 Polchert D, Sobinsky J, Douglas G, Kidd M, Moadsiri A, Reina E et al. IFN-gamma activation of mesenchymal stem cells for treatment and prevention of graft versus host disease. Eur J Immunol 2008; 38: 1745-1755.

48 Miura Y. Human bone marrow mesenchymal stromal/stem cells: current clinical applications and potential for hematology. Int J Hematol 2016; 103: $122-128$.

49 Chen W, Li M, Li Z, Yan Z, Cheng H, Pan B et al. CXCR4-transduced mesenchymal stem cells protect mice against graft-versus-host disease. Immunol Lett 2012; 143: 161-169.

50 Li H, Jiang $Y$, Jiang X, Guo X, Ning H, Li Y et al. CCR7 guides migration of mesenchymal stem cell to secondary lymphoid organs: a novel approach to separate GvHD from GvL effect. Stem Cells 2014; 32: 1890-1903.

51 Restifo NP, Dudley ME, Rosenberg SA. Adoptive immunotherapy for cancer: harnessing the T cell response. Nat Rev Immunol 2012; 12: 269-281.

52 Heslop HE, Slobod KS, Pule MA, Hale GA, Rousseau A, Smith CA et al. Long-term outcome of EBV-specific T-cell infusions to prevent or treat EBV-related lymphoproliferative disease in transplant recipients. Blood 2010; 115: 925-935.

53 Maude SL, Frey N, Shaw PA, Aplenc R, Barrett DM, Bunin NJ et al. Chimeric antigen receptor $T$ cells for sustained remissions in leukemia. N Engl J Med 2014; 371: 1507-1517.

54 Chambers CA, Sullivan TJ, Allison JP. Lymphoproliferation in CTLA-4-deficient mice is mediated by costimulation-dependent activation of CD4+ T cells. Immunity 1997; 7: 885-895.

55 Feau S, Arens R, Togher S, Schoenberger SP. Autocrine IL-2 is required for secondary population expansion of CD8(+) memory T cells. Nat Immunol 2011; 12: 908-913.

56 Waterhouse $P$, Penninger JM, Timms E, Wakeham A, Shahinian A, Lee KP et al. Lymphoproliferative disorders with early lethality in mice deficient in ctla-4. Science 1995; 270: 985-988. 
57 Auletta JJ, Eid SK, Wuttisarnwattana P, Silva I, Metheny L, Keller MD et al. Human mesenchymal stromal cells attenuate graft-versus-host disease and maintain graft-versus-leukemia activity following experimental allogeneic bone marrow transplantation. Stem Cells 2015; 33: 601-614.

58 Baron F, Lechanteur C, Willems E, Bruck F, Baudoux E, Seidel L et al. Cotransplantation of mesenchymal stem cells might prevent death from graft-versus-host disease (GVHD) without abrogating graft-versus-tumor effects after HLA-mismatched allogeneic transplantation following nonmyeloablative conditioning. Biol Blood Marrow Transplant 2010; 16: 838-847.

59 English K, French A, Wood KJ. Mesenchymal stromal cells: facilitators of successful transplantation? Cell Stem Cell 2010; 7: 431-442.

60 Kebriaei P, Isola L, Bahceci E, Holland K, Rowley S, McGuirk J et al. Adult human mesenchymal stem cells added to corticosteroid therapy for the treatment of acute graft-versus-host disease. Biol Blood Marrow Transplant 2009; 15: 804-811.

61 Kurtzberg J, Prockop S, Teira P, Bittencourt H, Lewis V, Chan KW et al. Allogeneic human mesenchymal stem cell therapy (remestemcel-L, Prochymal) as a rescue agent for severe refractory acute graft-versus-host disease in pediatric patients. Biol Blood Marrow Transplant 2014; 20: 229-235.

62 Nemeth K, Keane-Myers A, Brown JM, Metcalfe DD, Gorham JD, Bundoc VG et al. Bone marrow stromal cells use TGF-beta to suppress allergic responses in a mouse model of ragweed-induced asthma. Proc Natl Acad Sci USA 2010; 107: 5652-5657.

63 Guo J, Yang J, Cao G, Fan H, Guo C, Ma YE et al. Xenogeneic immunosuppression of human umbilical cord mesenchymal stem cells in a major histocompatibility complex-mismatched allogeneic acute graft-versus-host disease murine model. Eur J Haematol 2011; 87: 235-243.

64 Dave M, Hayashi Y, Gajdos GB, Smyrk TC, Svingen PA, Kvasha SM et al. Stem cells for murine interstitial cells of cajal suppress cellular immunity and colitis via prostaglandin E2 secretion. Gastroenterology 2015; 148: 978-990.

65 Chinnadurai R, Copland IB, Ng S, Garcia M, Prasad M, Arafat D et al. Mesenchymal stromal cells derived from Crohn's patients deploy indoleamine 2,3-dioxygenase-mediated immune suppression, independent of autophagy. Mol Ther 2015; 23: 1248-1261.

66 Ling W, Zhang J, Yuan Z, Ren G, Zhang L, Chen X et al. Mesenchymal stem cells use IDO to regulate immunity in tumor microenvironment. Cancer Res 2014; 74: 1576-1587.

67 Zhang Q, Shi S, Liu Y, Uyanne J, Shi Y, Shi S et al. Mesenchymal stem cells derived from human gingiva are capable of immunomodulatory functions and ameliorate inflammation-related tissue destruction in experimental colitis. J Immunol 2009; 183: 7787-7798.

68 Qu X, Liu X, Cheng K, Yang R, Zhao RC. Mesenchymal stem cells inhibit Th17 cell differentiation by IL-10 secretion. Exp Hematol 2012; 40: 761-770.

69 Leibacher J, Henschler R. Biodistribution, migration and homing of systemically applied mesenchymal stem/stromal cells. Stem Cell Res Ther 2016; 7: 7

This work is licensed under a Creative Commons Attribution-NonCommercial-ShareAlike 4.0 International License. The images or other third party material in this article are included in the article's Creative Commons license, unless indicated otherwise in the credit line; if the material is not included under the Creative Commons license, users will need to obtain permission from the license holder to reproduce the material. To view a copy of this license, visit http:// creativecommons.org/licenses/by-nc-sa/4.0/

Supplementary Information accompanies the paper on Experimental \& Molecular Medicine website (http://www.nature.com/emm) 